\title{
Magnesium intake and vascular structure and function: the Hoorn Study
}

\author{
Emma A. Vermeulen ${ }^{1}$ (D) Hanne B. T. de Jong ${ }^{2} \cdot$ Alexander G. A. Blomjous $^{3} \cdot$ Coby Eelderink $^{4} \cdot$ Tiny Hoekstra $^{1}$. \\ Petra J. M. Elders ${ }^{5} \cdot$ Martin H. de Borst ${ }^{4} \cdot$ Marc G. Vervloet ${ }^{1}$. Adriana J. van Ballegooijen ${ }^{1,6}$. Joline W. Beulens ${ }^{6}$
}

Received: 11 February 2021 / Accepted: 20 August 2021 / Published online: 7 September 2021

(c) The Author(s) 2021

\begin{abstract}
Purpose Circulating and dietary magnesium have been shown to be inversely associated with the prevalence of cardiovascular disease (CVD) and mortality in both high and low-risk populations. We aimed to examine the association between dietary magnesium intake and several measures of vascular structure and function in a prospective cohort.

Methods We included 789 participants who participated in the vascular screening sub-cohort of the Hoorn Study, a population-based, prospective cohort study. Baseline dietary magnesium intake was estimated with a validated food frequency questionnaire and categorised in energy-adjusted magnesium intake tertiles. Several measurements of vascular structure and function were performed at baseline and most measurements were repeated after 8 years of follow-up $(n=432)$. Multivariable linear and logistic regression was performed to study the cross-sectional and longitudinal associations of magnesium intake and intima-media thickness (IMT), augmentation index (Aix), pulse wave velocity (PWV), flow-mediated dilatation (FMD), and peripheral arterial disease (PAD).

Results Mean absolute magnesium intake was $328 \pm 83 \mathrm{mg} /$ day and prior CVD and DM2 was present in 55 and $41 \%$ of the participants, respectively. Multivariable regression analyses did not demonstrate associations between magnesium intake and any of the vascular outcomes. Participants in the highest compared to the lowest magnesium intake tertile demonstrated in fully adjusted cross-sectional analyses a PWV of $-0.21 \mathrm{~m} / \mathrm{s}(95 \%$ confidence interval $-1.95,1.52)$, a FMD of $-0.03 \%$ $(-0.89,0.83)$ and in longitudinal analyses an IMT of $0.01 \mathrm{~mm}(-0.03,0.06)$, an Aix of $0.70 \%(-1.69,3.07)$ and an odds ratio of $0.84(0.23,3.11)$ for $\mathrm{PAD}$
\end{abstract}

Conclusion We did not find associations between dietary magnesium intake and multiple markers of vascular structure and function, in either cross-sectional or longitudinal analyses.

Keywords Magnesium intake $\cdot$ Intima-media thickness $\cdot$ Flow-mediated dilatation $\cdot$ Pulse wave velocity $\cdot$ Augmentation index $\cdot$ Peripheral arterial disease

Joline W. Beulens

j.beulens@amsterdamumc.nl

1 Department of Nephrology, Amsterdam UMC, Location VUmc, Amsterdam, The Netherlands

2 Division of Human Nutrition and Health, Wageningen University and Research, Wageningen, The Netherlands

3 VUmc Medical Faculty, Amsterdam, The Netherlands

4 Division of Nephrology, Department of Internal Medicine, University Medical Center Groningen, University of Groningen, Groningen, The Netherlands
5 Department of General Practice and Elderly Care Medicine, Amsterdam Public Health Research Institute, Amsterdam UMC, Location VUmc, Amsterdam, The Netherlands

6 Department of Epidemiology and Biostatistics, Amsterdam Public Health Institute, Amsterdam UMC, Location VUmc, De Boelelaan 1117, 1081 HV Amsterdam, The Netherlands 


\section{Introduction}

Cardiovascular disease (CVD) is one of the most common morbidities and the leading cause of death worldwide [1, 2]. In addition to traditional risk factors of CVD, such as physical inactivity, tobacco use, hypertension, hypercholesterolemia, obesity and diabetes, magnesium deficiency gained interest during recent years as a potentially modifiable risk factor of CVD [3-8].

As one of the most abundant intracellular cations, magnesium is required for normal cell physiology and is essential for neuromuscular and cardiovascular function [9]. Several systematic reviews and meta-analyses demonstrated an association between high serum or dietary magnesium and a reduced risk of all-cause and cardiovascular mortality, CVD including coronary heart disease and ischemic stroke, hypertension, and type 2 diabetes (DM2) within the general population [3-7, 10]. Part of this association might be explained by the protective effects of magnesium on vascular calcification, vascular tone, endothelial cell function and low-grade inflammation, influencing both vascular structure and function $[9,11]$. The calcification inhibiting effects of magnesium have been demonstrated in animal studies as well [12-15]. Literature on the association between magnesium intake, and markers of vascular structure and function in humans is very limited, while many studies do report on the associations with serum magnesium concentration [16-22], or the effects of magnesium supplementation [23-28]. Yet, besides magnesium concentration and magnesium supplementation, the role of magnesium intake from dietary sources (among others leafy vegetables, nuts, whole grains and seeds) could be of importance in the prevention of vascular impairment on a public health level and for dietary guidelines. Only a few studies investigated the association between dietary magnesium intake and intima-media thickness (IMT) or pulse wave velocity (PWV) [29-32]. However, these studies did not observe consistent associations and were mostly performed cross-sectionally in high-risk populations such as DM2 or chronic kidney disease cohorts. No studies reported on magnesium intake in relation to flow-mediated dilatation (FMD), augmentation index (Aix) or peripheral artery disease (PAD). These vascular markers have been measured in a sub-cohort of the Hoorn study, a population-based prospective cohort in the Netherlands that was initiated to study the prevalence and risk factors of impaired glucose metabolism and DM2.

Therefore, the aim of this study was to examine whether dietary magnesium intake is associated with vascular markers IMT, FMD, PWV, Aix and PAD, cross-sectionally and after 8 years of follow-up in individuals of the vascular screening sub-cohort of the Hoorn study.

\section{Methods}

\section{Study population}

The Hoorn Study is a prospective, population-based cohort of Dutch citizens, initiated in 1989 in the Hoorn region. This cohort has been described in detail previously [33]. In brief, 3553 Caucasian men and women, aged between 50 to 75 years, were randomly selected from the municipal registry of the city of Hoorn, resulting in 2484 participants that provided informed consent. For the present study, we used data of a vascular screening sub-cohort $(n=831)$ with additional questionnaires and several measurements of vascular structure and function in 2000-2001, which was considered baseline. This sub-cohort was oversampled for individuals with DM2 and impaired glucose metabolism (IGM) to investigate effect modification by glucose metabolism status [33, 34]. Participants with a missing food frequency questionnaire (FFQ) $(n=20)$ and without any available vascular measurements of interest $(n=22)$ at baseline were excluded from the current analyses, resulting in 789 participants (Fig. 1). Follow-up visits of this vascular screening subcohort were performed in 2007-2009 in 432 participants, with repeated measurement of at least one of the vascular measurements. Absence of follow-up visit was due to death $(n=128)$, inability to participate due to poor health status or relocation $(n=52)$, too many missings in previous visit $(n=12)$ and untraceable or unknown reason $(n=165)$. The study was approved by the Ethics Committee of the VU University Medical Centre (Amsterdam, the Netherlands).

\section{Magnesium intake assessment}

Magnesium intake at baseline was assessed based on a validated, 178 item food frequency questionnaire (FFQ), estimating specific food consumption over the previous year. This FFQ demonstrated correlation coefficients of $\geq 0.61$ for fibre and macronutrients and $0.32-0.78$ for specific food groups high in magnesium content (bread, cereals, vegetables, nuts and seeds), in comparison to multiple $24 \mathrm{~h}$ dietary recalls $[35,36]$. Participants filled out the FFQ at home and these questionnaires were checked for completeness after return. Nutrient intake, including magnesium and dietary fibre intake, was calculated by multiplying the amount and frequency of consumption of each food item by its nutrient content using the Dutch Food Composition Table (NEVO) 1993 [37]. Finally, for each nutrient, the total intake was summed for all food items, resulting in a mean nutrient specific, daily intake. No data on supplement use was available, therefore, magnesium intake is defined as solely dietary intake of magnesium. 
Fig. 1 Flow chart of study population. $D M$ diabetes mellitus, $F F Q$ food frequency questionnaire. *Ref: Spijkerman AM, et al. Diabetes Care. 2002 [34].

***oor health status included illness, reduced mobility, high age and dementia

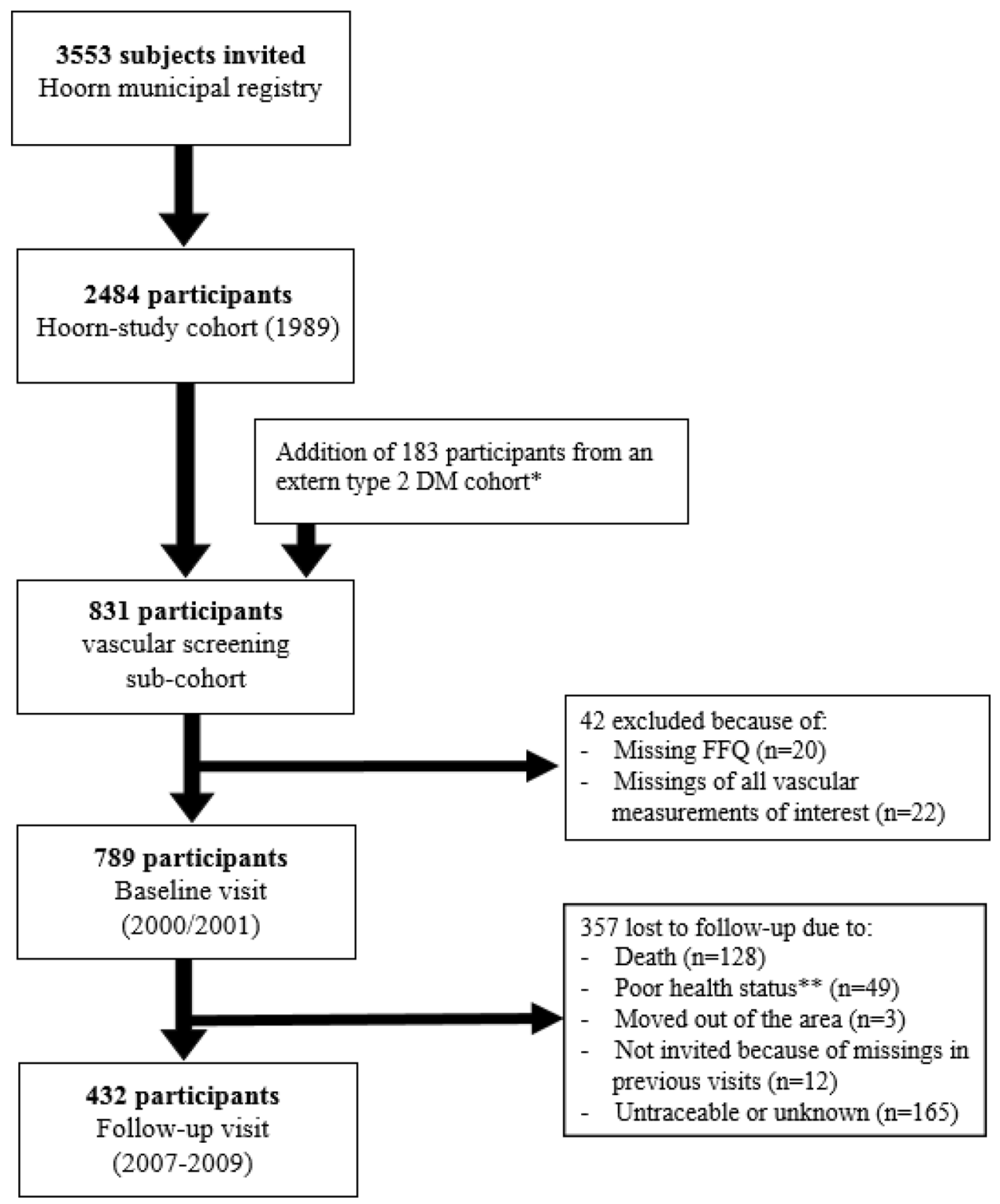

\section{Measurements of vascular structure and function}

At baseline, IMT, Aix, PWV, FMD and ankle-brachial index (ABI) were measured by a trained researcher. At the follow-up visit, measurements of IMT, ABI and Aix were repeated. A short description of each of the five markers of vascular structure and function is listed below, more detailed descriptions of each vascular measure are published previously [38-45]. Measurements of the IMT were performed at the location of the common carotid artery using an ultrasound device and we applied the mean of multiple measurements within the analyses [38]. The FMD was assessed through ultrasound examination of the diameter of the brachial artery before and after pressure cuff inflation [39]. FMD is expressed as a percentage and calculated as the mean of three measurements of the maximum diameter after pressure cuff inflation minus the baseline diameter, divided by the baseline diameter. Measurements of both Aix and PWV were performed using the Sphygmocor, AtCor Medical device, measuring the radial artery, and carotid and femoral arteries, respectively [40,41]. The Aix is expressed as a percentage and calculated as augmentation pressure divided by the tonometrically derived pulse pressure. The carotid-femoral travelled distance was estimated using body height, conform the formula proposed by Weber et al. (body height/4 + 7.28) $[42,43]$. Subsequently, the carotid-femoral PWV was calculated as travelled distance in meters divided by transit time in seconds. The ABI was calculated using Doppler-assisted systolic blood pressure measurements at both sides [44, 45]. The clinical cut off of the left or right $\mathrm{ABI}$ to classify as a peripheral arterial disease (PAD) was a value below 0.9 [46]. 


\section{Other determinants}

Hypertension is defined as systolic blood pressure $\geq 140 \mathrm{mmHg}$, diastolic blood pressure $\geq 90 \mathrm{mmHg}$ or the use of antihypertensive medication. Glucose status is classified according to the WHO criteria (1999) of normal glucose metabolism (NGM), IGM and DM2 [47]. Information on prior CVD was extracted through medical records in combination with the Rose Angina Questionnaire [48]. Subjects filled out multiple questionnaires to obtain information about education level (low, middle, high), smoking status (never, former, current), self-reported physical activity (hours/week), dietary intake (FFQ) and alcohol consumption (no consumption, 0-13 glasses per week, $\geq 14$ glasses per week) $[33,35]$. All laboratory values were acquired after overnight fasting and included glucose, haemoglobin A1c (HbA1c), total cholesterol, low-density lipoprotein cholesterol (LDL-cholesterol), high-density lipoprotein cholesterol (HDL-cholesterol), triglycerides, C-reactive protein (CRP), and serum creatinine (Jaffe method). Estimated glomerular filtration rate (eGFR) was calculated according to the chronic kidney disease epidemiology collaboration (CKDEPI 2009) [49].

\section{Statistical analyses}

We adjusted all dietary intake variables for energy intake using the residual method [50]. Due to differences in total energy intake and sex-specific magnesium intake recommendations, we classified participants into sex-specific tertiles according to their energy-adjusted magnesium intake. The classification into tertiles was separately performed for the cross-sectional (full-cohort) and longitudinal analyses sample (only including those with follow-up measurements). Baseline characteristics are displayed for the magnesium intake tertiles. Variables are displayed as mean and standard deviation when normally distributed, as median and interquartile range [IQR] when the distribution was skewed and for categorical variables as percentage. To examine trends across the magnesium intake tertiles, we performed linear regression analyses or chi-square (Mantel-Haenszel test) for continuous and categorical variables respectively, with magnesium tertiles as a continuous determinant. For this purpose, we first performed a log-transformation for those continuous variables with a right-skewed distribution.

We performed multiple linear regression analyses to investigate the associations between magnesium intake tertiles and IMT, FMD, PWV and Aix, and logistic regression for the association with PAD. The lowest magnesium intake tertile was considered as the reference category. IMT, Aix and PAD were analysed prospectively as well, by adding time and the baseline value as an independent variable to the regression models. In the longitudinal analysis of PAD, cases with PAD at baseline were excluded $(n=7)$. Both PWV and FMD were analysed cross-sectionally only, since these measurements were not repeated during the follow-up visit.

We defined three a priori nested models to adjust for potential confounding in all analyses. The first model is adjusted for age, sex and glucose metabolism status. The second model is additionally adjusted for prior CVD, smoking status and systolic blood pressure. The third model also included energy intake and energy-adjusted fibre intake. Effect modification by age (above or below the median age of 68), glucose status (NGM, IGM or DM2) and prior CVD (yes or no) was tested by adding interaction terms to the regression models with magnesium as a continuous variable. Stratified analyses were performed when significant interaction terms were found $(p<0.10)$ and confirmed with interaction terms for the magnesium intake tertiles.

For the 32 participants with missing data on covariates in the above specified regression models (with a maximum of $3 \%$ missing for each covariate), we imputed missing data using multiple imputation with predictive mean matching (10 sets of 10 iterations each). Missing covariates at baseline were CVD $(n=23)$, glucose metabolism status $(n=2)$, smoking $(n=5)$, systolic blood pressure $(n=2)$, glucose status $(n=2)$. We imputed separately for cross-sectional and longitudinal data sets. For the longitudinal analyses, missing data of outcome variables at follow-up (IMT $n=11$, Aix $n=29$, ABI $n=6$ ) were imputed, however, we did not impute missing data in outcome variables at baseline (up to $19 \%$ missing). Therefore, those cases were not included in the longitudinal analyses. We checked imputation of continuous variables by visual inspection of the convergence plots. Sensitivity analyses were performed for complete case analysis and absolute intake tertiles variables, based on the absolute instead of energy-adjusted magnesium intake.

We performed all analyses using IBM SPSS Statistics 24.0 (IBM Corp., Armonk, NY). Two-sided $p$ values $<0.05$ were considered statistically significant.

\section{Results}

\section{Participant characteristics}

Participant characteristics at baseline are presented according to sex-specific and energy-adjusted magnesium intake tertiles (Table 1). The mean age was $68.5 \pm 7.2$ years and $398(51 \%)$ of the participants were men. DM2 and IGM was present in $41 \%$ and $23 \%$ of the participants, respectively, and $55 \%$ of the participants had a history of CVD. Mean absolute magnesium intake was $328 \pm 83 \mathrm{mg} / \mathrm{day}$, with a mean of $353 \pm 87 \mathrm{mg} /$ day for men and $303 \pm 70 \mathrm{mg} /$ day for 
Table 1 Baseline characteristics of the vascular screening sub-cohort of the Hoorn study according to sex-specific and energy-adjusted magnesium intake tertiles $(n=789)$

\begin{tabular}{|c|c|c|c|c|}
\hline & \multirow[t]{2}{*}{ Total cohort } & \multicolumn{3}{|c|}{ Magnesium intake tertiles } \\
\hline & & Tertile 1 & Tertile 2 & Tertile 3 \\
\hline$N$ & 789 & 262 & 264 & 263 \\
\hline Median magnesium intake, $\mathrm{mg} / \mathrm{day}$ & 328 & 282 & 328 & 371 \\
\hline $\begin{array}{l}\text { Range of magnesium intake } \\
(\min -\max ), \mathrm{mg} / \text { day }\end{array}$ & $136-530$ & $136-313$ & $303-350$ & $345-530$ \\
\hline \multicolumn{5}{|l|}{ Demographics } \\
\hline Age, years* & $68.5 \pm 7.2$ & $69.2 \pm 7.4$ & $68.9 \pm 7.4$ & $67.3 \pm 6.7$ \\
\hline Male, $n(\%)$ & $404(51)$ & $133(51)$ & $134(51)$ & $134(51)$ \\
\hline \multicolumn{5}{|l|}{ Education level, $n(\%)^{*}$} \\
\hline Low & $398(51)$ & $138(54)$ & $139(53)$ & $121(47)$ \\
\hline Intermediate & $294(38)$ & $98(38)$ & $93(35)$ & $103(40)$ \\
\hline High & $89(11)$ & $22(9)$ & $31(12)$ & $36(14)$ \\
\hline \multicolumn{5}{|l|}{ Lifestyle } \\
\hline \multicolumn{5}{|l|}{ Smoking status, $n(\%) *$} \\
\hline Current & $136(17)$ & $61(24)$ & $47(18)$ & $28(11)$ \\
\hline Former & $360(46)$ & $112(43)$ & $124(47)$ & $124(47)$ \\
\hline Never & $288(37)$ & $87(34)$ & $91(35)$ & $110(42)$ \\
\hline Physical activity, h/week* & $18.4[9.0-29.0]$ & $15.5[7.5-27.8]$ & $19.2[9.5-31.0]$ & $19.0[9.7-28.0]$ \\
\hline \multicolumn{5}{|l|}{ Alcohol consumption, $n(\%)$} \\
\hline No consumption & $142(18)$ & $46(18)$ & $50(19)$ & $46(18)$ \\
\hline $0-13$ glasses per week & $482(61)$ & $151(58)$ & $164(62)$ & $167(64)$ \\
\hline$\geq 14$ glasses per week & $165(21)$ & $65(25)$ & $50(19)$ & $50(19)$ \\
\hline BMI, $\mathrm{kg} / \mathrm{m}^{2}$ & $27.7 \pm 4.0$ & $27.4 \pm 3.9$ & $27.8 \pm 3.8$ & $27.8 \pm 4.3$ \\
\hline \multicolumn{5}{|l|}{ Clinical characteristics } \\
\hline \multicolumn{5}{|l|}{ Glucose status, $n(\%)$} \\
\hline Normal glucose metabolism & $287(36)$ & $91(35)$ & $92(35)$ & $103(39)$ \\
\hline Impaired glucose metabolism & $181(23)$ & $64(25)$ & $62(24)$ & $55(21)$ \\
\hline Type 2 diabetes mellitus & $320(41)$ & $106(41)$ & $109(41)$ & $105(40)$ \\
\hline Prior CVD, $n(\%)^{*}$ & $417(54)$ & $152(60)$ & $133(52)$ & $132(51)$ \\
\hline Hypertension, $n(\%)$ & $552(70)$ & $184(70)$ & $183(70)$ & $185(70)$ \\
\hline Systolic blood pressure, $\mathrm{mmHg}$ & $142 \pm 20$ & $141 \pm 19$ & $143 \pm 20$ & $142 \pm 22$ \\
\hline $\mathrm{HbA} 1 \mathrm{c}, \mathrm{mmol} / \mathrm{mol}$ & $43.2 \pm 8.5$ & $42.3 \pm 8.4$ & $43.3 \pm 8.1$ & $43.5 \pm 9.3$ \\
\hline Triglycerides, $\mathrm{mmol} / \mathrm{l}$ & $1.4[1.0-1.9]$ & $1.4[1.0-1.9]$ & $1.4[1.0-1.9]$ & $1.4[1.0-1.8]$ \\
\hline Total cholesterol, mmol/l & $5.7 \pm 1.0$ & $5.7 \pm 1.0$ & $5.7 \pm 1.0$ & $5.7 \pm 1.1$ \\
\hline LDL cholesterol, mmol/l & $3.6 \pm 0.9$ & $3.5 \pm 0.9$ & $3.6 \pm 0.9$ & $3.7 \pm 0.9$ \\
\hline HDL cholesterol, mmol/l & $1.4 \pm 0.4$ & $1.4 \pm 0.4$ & $1.4 \pm 0.4$ & $1.4 \pm 0.4$ \\
\hline $\mathrm{CRP}, \mathrm{mg} / \mathrm{l}^{*}$ & $2.0[0.8-4.0]$ & $2.1[1.1-4.4]$ & $2.1[1.1-4.3]$ & $1.6[0.7-3.5]$ \\
\hline $\mathrm{eGFR}, \mathrm{ml} / \mathrm{min} / 1.73 \mathrm{~m}^{2} *$ & $81 \pm 14$ & $79 \pm 15$ & $83 \pm 12$ & $82 \pm 14$ \\
\hline Use of PPIs, $n(\%)^{*}$ & $33(4)$ & $16(6)$ & $12(5)$ & $5(2)$ \\
\hline \multicolumn{5}{|l|}{ Dietary intake } \\
\hline Energy intake, kcal/day & $1936 \pm 506$ & $1961 \pm 512$ & $1857 \pm 486$ & $1987 \pm 515$ \\
\hline Dietary fibre, g/day* & $23.3 \pm 4.9$ & $19.9 \pm 4.0$ & $23.2 \pm 3.7$ & $26.7 \pm 4.5$ \\
\hline Calcium intake, mg/day* & $1062 \pm 312$ & $883 \pm 229$ & $1092 \pm 273$ & $1209 \pm 336$ \\
\hline Phosphorus, mg/day* & $1439 \pm 240$ & $1248 \pm 178$ & $1469 \pm 175$ & $1596 \pm 220$ \\
\hline \multicolumn{5}{|l|}{ Vascular measurements } \\
\hline Intima-media thickness, mm & $0.86 \pm 0.19$ & $0.86 \pm 0.163$ & $0.86 \pm 0.18$ & $0.86 \pm 0.17$ \\
\hline Augmentation index, $\%$ & $32.4 \pm 8.7$ & $32.5 \pm 9.0$ & $33.2 \pm 8.7$ & $31.5 \pm 8.5$ \\
\hline Peripheral arterial disease, $n(\%)$ & $43(7.1)$ & $15(7.5)$ & $14(7.3)$ & (14) 6.7 \\
\hline Pulse wave velocity, $\mathrm{m} / \mathrm{s}$ & $10.3 \pm 5.2$ & $10.4 \pm 7.6$ & $10.5 \pm 3.3$ & $10.2 \pm 3.9$ \\
\hline Flow-mediated dilatation, $\%$ & $3.8 \pm .9$ & $3.7 \pm 4.2$ & $3.6 \pm 3.4$ & $4.0 \pm 3.9$ \\
\hline
\end{tabular}

Normally distributed data are presented as mean \pm standard deviation, non-normally distributed data as median [interquartile range], categorical data as \%. BMI body mass index, $C V D$ cardiovascular disease, $H b A 1 c$ haemoglobin A1c, $L D L$ low-density lipoprotein, $H D L$ high-density lipoprotein, $C R P$ C-reactive protein, $e G F R$ estimated glomerular filtration rate (CKD-EPI 2009), PPI proton-pump inhibitor. Intima-media thickness $n=733$, augmentation index $n=614$, peripheral arterial disease (ankle brachial 
Table 1 (continued)

index <0.9) $n=603$, pulse wave, velocity $n=317$, flow-mediated dilatation $n=635$. $* p$ trend $<0.05 * *$ Dietary intake is adjusted for total energy intake using the residual method. Tertiles are sex-specific and, therefore, values may overlap

women. Participants with lower magnesium intake were older, suffered more frequently from CVD, were more frequent smokers, less physically active, had higher triglycerides, higher CRP, lower eGFR, were more frequently proton pump inhibitor users, and had a lower fibre, calcium and phosphate intake. The mean of vascular measurements at baseline are presented in Table 1. In the case of IMT, Aix and PWV, a higher value represents worse vascular structure or function, while a higher FMD reflects better endothelial function.
Mean follow-up duration was $7.5 \pm 0.6$ year. Participants with a vascular follow-up visit were significantly younger and healthier, with less frequent DM2 or a history of CVD, and they had a slightly higher baseline magnesium intake compared to those with baseline measurements only. These differences were also reflected in more favourable baseline values of vascular measures for participants with follow-up measurements (Supplementary Table 1). Energy-adjusted magnesium intake correlated well with phosphate and fibre intake ( $r=0.64$ and $r=0.62$, respectively) and a weaker correlation was found for calcium $(r=0.44)$, all $p<0.01$.
Table 2 Cross-sectional association between sexspecific, energy-adjusted magnesium intake tertiles with intima-media thickness $(n=733)$, augmentation index $(n=614)$, pulse wave velocity $(n=317)$, flowmediated dilatation $(n=635)$ and peripheral arterial disease $(n=589)$

\begin{tabular}{|c|c|c|c|c|}
\hline & \multicolumn{3}{|c|}{ Magnesium intake tertiles* } & \multirow[t]{2}{*}{$p$ trend } \\
\hline & Tertile 1 & Tertile 2 & Tertile 3 & \\
\hline Median magnesium intake, mg/day & 282 & 328 & 371 & \\
\hline $\begin{array}{l}\text { Range of magnesium intake (min- } \\
\text { max), mg/day }\end{array}$ & $136-313$ & $303-350$ & $345-530$ & \\
\hline \multicolumn{5}{|l|}{ Beta $(95 \% \mathrm{CI})$} \\
\hline IMT (mm) & $n=237$ & $n=248$ & $n=248$ & \\
\hline Model 1 & Ref. (0.0) & $0.00(-0.03,0.03)$ & $0.01(-0.02,0.04)$ & 0.38 \\
\hline Model 2 & Ref. (0.0) & $0.00(-0.03,0.03)$ & $0.01(-0.02,0.04)$ & 0.38 \\
\hline Model 3 & Ref. (0.0) & $0.00(-0.03,0.03)$ & $0.02(-0.02,0.05)$ & 0.31 \\
\hline Aix $(\%)$ & $n=201$ & $n=200$ & $n=113$ & \\
\hline Model 1 & Ref. (0.0) & $0.25(-1.33,1.82)$ & $-0.97(-2.53,0.59)$ & 0.22 \\
\hline Model 2 & Ref. (0.0) & $0.38(-1.18,1.94)$ & $-0.49(-2.05,1.06)$ & 0.53 \\
\hline Model 3 & Ref. (0.0) & $0.56(-1.11,2.23)$ & $0.24(-1.65,2.14)$ & 0.81 \\
\hline $\mathrm{PWV}(\mathrm{m} / \mathrm{s})$ & $n=99$ & $n=111$ & $n=107$ & \\
\hline Model 1 & Ref. (0.0) & $-0.05(-1.44,1.34)$ & $0.08(-1.33,1.50)$ & 0.91 \\
\hline Model 2 & Ref. (0.0) & $-0.07(-1.40,1.25)$ & $0.13(-1.23,1.49)$ & 0.85 \\
\hline Model 3 & Ref. (0.0) & $-0.31(-1.79,1.17)$ & $-0.21(-1.95,1.52)$ & 0.82 \\
\hline FMD $(\%)$ & $n=210$ & $n=206$ & $n=219$ & \\
\hline Model 1 & Ref. (0.0) & $-0.08(-0.80,0.64)$ & $0.10(-0.61,0.81)$ & 0.78 \\
\hline Model 2 & Ref. (0.0) & $-0.12(-0.83,0.59)$ & $-0.07(-0.77,0.63)$ & 0.85 \\
\hline Model 3 & Ref. (0.0) & $-0.04(-0.79,0.70)$ & $-0.03(-0.89,0.83)$ & 0.94 \\
\hline \multicolumn{5}{|l|}{ OR $(95 \%$ CI $)$} \\
\hline $\mathrm{ABI}$ prevalent $\mathrm{PAD}$ & $\begin{array}{l}n=201 \\
n=15\end{array}$ & $\begin{array}{l}n=192 \\
n=14\end{array}$ & $\begin{array}{l}n=196 \\
n=14\end{array}$ & \\
\hline Model 1 & Ref. (1.0) & $1.00(0.46,2.16)$ & $1.02(0.47,2.21)$ & 0.96 \\
\hline Model 2 & Ref. (1.0) & $1.19(0.52,2.71)$ & $1.50(0.64,3.52)$ & 0.36 \\
\hline Model 3 & Ref. (1.0) & $1.30(0.54,3.18)$ & $1.75(0.63,4.88)$ & 0.28 \\
\hline
\end{tabular}

Model 1: age, sex and glucose status;

Model 2: model 1+ prior CVD, smoking status and systolic blood pressure;

Model 3: model 2+ caloric intake and energy-adjusted fibre intake

$A B I$ ankle-brachial index, Aix augmentation index, $C I$ confidence interval, $C V D$ cardiovascular disease, $F M D$ flow-mediated dilatation, $I M T$ intima-media thickness, $M g$ magnesium, $O R$ odds ratio, $P A D$ peripheral artery disease $(\mathrm{ABI}<0.9), P W V$ pulse wave velocity, Ref. reference category

*Dietary intake is adjusted for total energy intake using the residual method. Tertiles are sex-specific and therefore magnesium intake values may overlap 


\section{Cross-sectional associations}

Measurements of vascular structure and function at baseline did not differ significantly between the magnesium intake tertiles (Table 1). No crude or multivariable-adjusted crosssectional associations were observed between magnesium intake tertiles and PWV, FMD, IMT, Aix or prevalent PAD (Table 2). For FMD, results were also stratified according to the presence of CVD at baseline, because of a significant interaction between magnesium intake and prior CVD $(p=0.03)$. However, stratification did not considerably change these results (Supplementary Table 2). We found no effect modification by age, sex or glucose metabolism status for any of the vascular outcome measures (all $p$ values $>0.10$ ).

\section{Longitudinal associations}

Overall, both IMT and Aix increased significantly from a mean IMT of $0.84 \pm 0.16 \mathrm{~mm}$ at baseline to $0.88 \pm 0.16 \mathrm{~mm}$ at follow up, and a mean Aix of $31.4 \pm 8.6 \%-34.2 \pm 8.4 \%$, both $p<0.01$. Absolute outcome and changes of IMT, Aix and incident PAD after 8 year of follow-up did not differ significantly across magnesium intake tertiles (Table 3). After full adjustment, we did not observe associations between the magnesium intake tertiles and any of these vascular measurements (Table 4). We found no effect modification by age, sex, glucose metabolism status or prior CVD.

\section{Sensitivity analysis}

Complete case analysis including, 757 and 417 participants for the cross-sectional and longitudinal cohorts, respectively, did not change the results for any of the vascular outcomes (Supplementary Table 3 and 4). The sensitivity analysis with absolute magnesium intake tertiles and energy-unadjusted intake variables did not considerably change the results (Supplementary Table 5 and 6). Although the cross-sectional energy-unadjusted analysis of Aix demonstrated a lower Aix for the highest compared to the lowest magnesium tertile, $-1.71 \%$ (95\% confidence interval $-3.27,-0.14)$ and $p$ trend $<0.01$, adding fibre intake to the model erased this inverse association (Supplementary Table 5).

\section{Discussion}

We found no evidence for cross-sectional or longitudinal associations between dietary magnesium intake and markers of vascular structure and function including IMT, Aix, PWV, FMD and PAD.

Our results confirm the very limited previous literature on magnesium intake and these vascular makers. In two large
Table 3 Markers of vascular structure and function at baseline and after 8 years of follow-up for all participants with follow-up measurements of intimal media thickness, augmentation index and anklebrachial index, according to sex-specific and energy-adjusted magnesium intake tertiles $(n=432)$

\begin{tabular}{lllll}
\hline & \multicolumn{2}{l}{ Magnesium intake tertiles* } & \multirow{2}{*}{$p$ trend } \\
\cline { 2 - 3 } & Tertile 1 & Tertile 2 & Tertile 3 & \\
\hline Median magnesium intake, mg/day & 291 & 338 & 381 \\
Range of magnesium intake (min- & $150-325$ & $310-359$ & $353-542$ & \\
max), mg/day & & & & \\
IMT (mm) & $n=133$ & $n=136$ & $n=135$ & \\
Baseline & $0.84 \pm 0.14$ & $0.84 \pm 0.17$ & $0.84 \pm 0.17$ & 0.80 \\
Follow-up & $0.87 \pm 0.15$ & $0.88 \pm 0.15$ & $0.88 \pm 0.17$ & 0.46 \\
Delta IMT & $0.04 \pm 0.17$ & $0.04 \pm 0.18$ & $0.04 \pm 0.19$ & 0.67 \\
Aix (\%) & $n=115$ & $n=107$ & $n=110$ & \\
Baseline & $31.1 \pm 8.8$ & $32.5 \pm 8.7$ & $30.8 \pm 8.3$ & 0.78 \\
Follow-up & $33.1 \pm 9.1$ & $35.1 \pm 7.7$ & $34.6 \pm 8.0$ & 0.16 \\
Delta Aix & $2.0 \pm 9.2$ & $2.6 \pm 9.2$ & $3.9 \pm 9.4$ & 0.12 \\
ABI & $n=116$ & $n=114$ & $n=115$ & \\
Prevalent PAD, $n(\%)$ & $2(1.7)$ & $3(2.6)$ & $2(1.7)$ & \\
Incident PAD**, $n(\%)$ & $13 / 114(11.4)$ & $11 / 111(9.9)$ & $10 / 103(8.8)$ & 0.53 \\
\hline
\end{tabular}

Data are presented as mean \pm standard deviation, categorical data as $\mathrm{n}(\%)$

IMT $n=404$, Aix $n=332$, ABI $n=345$

$A B I$ Ankle-brachial index, Aix augmentation index, IMT intima-media thickness, $M g$ magnesium, $P A D$ peripheral artery disease $(\mathrm{ABI}<0.9)$

*Dietary intake is adjusted for total energy intake using the residual method. Tertiles are sex-specific and, therefore, values may overlap

**The reported number of incident PAD are with the exclusion of prevalent PAD cases 
Table 4 Longitudinal association between sexspecific, energy-adjusted magnesium intake tertiles with intima-media thickness $(n=415)$, augmentation index $(n=361)$ and the odds ratio of incident peripheral artery disease $(n=344)$ at 8 years of follow-up

\begin{tabular}{|c|c|c|c|c|}
\hline & \multicolumn{3}{|c|}{ Magnesium intake tertiles* } & \multirow[t]{2}{*}{$p$ trend } \\
\hline & Tertile 1 & Tertile 2 & Tertile 3 & \\
\hline Median magnesium intake, mg/day & 291 & 338 & 381 & \\
\hline $\begin{array}{l}\text { Range of magnesium intake (min- } \\
\max \text { ), mg/day }\end{array}$ & $150-325$ & $310-359$ & $353-542$ & \\
\hline \multicolumn{5}{|l|}{ Beta $(95 \%$ CI $)$} \\
\hline IMT (mm) & $n=137$ & $n=140$ & $n=138$ & \\
\hline Model 1 & Ref. (0.0) & $0.01(-0.03,0.04)$ & $0.02(-0.02,0.05)$ & 0.37 \\
\hline Model 2 & Ref. (0.0) & $0.01(-0.03,0.04)$ & $0.02(-0.02,0.05)$ & 0.31 \\
\hline Model 3 & Ref. (0.0) & $0.00(-0.04,0.04)$ & $0.01(-0.03,0.06)$ & 0.57 \\
\hline Aix (\%) & $n=122$ & $n=117$ & $n=122$ & \\
\hline Model 1 & Ref. (0.0) & $1.59(-0.40,3.57)$ & $1.76(-0.20,3.72)$ & 0.08 \\
\hline Model 2 & Ref. (0.0) & $1.65(-0.33,3.63)$ & $1.76(-0.20,3.72)$ & 0.08 \\
\hline Model 3 & Ref. (0.0) & $1.04(-1.06,3.15)$ & $0.70(-1.69,3.07)$ & 0.56 \\
\hline \multicolumn{5}{|l|}{ OR $(95 \% \mathrm{CI})$} \\
\hline ABI & $n=114$ & $n=114$ & $n=116$ & \\
\hline Incident PAD & $n=13$ & $n=12$ & $n=12$ & \\
\hline Model 1 & Ref. (1.0) & $0.67(0.23,1.92)$ & $0.99(0.34,2.89)$ & 0.92 \\
\hline Model 2 & Ref. (1.0) & $0.61(0.20,1.84)$ & $0.94(0.31,2.85)$ & 0.86 \\
\hline Model 3 & Ref. (1.0) & $0.59(0.18,1.88)$ & $0.84(0.23,3.11)$ & 0.77 \\
\hline
\end{tabular}

*Dietary intake is adjusted for total energy intake using the residual method. Tertiles are sex-specific and, therefore, values may overlap

Model 1: age, sex and glucose status;

Model 2: model 1+ prior CVD, smoking status and systolic blood pressure;

Model 3: model 2+ caloric intake and energy adjusted fibre intake

$A B I$ ankle-brachial index, Aix augmentation index, $C I$ confidence interval, IMT intima-media thickness, $O R$ odds ratio, $P A D$ peripheral artery disease, Ref. reference category. The longitudinal associations are adjusted for time of follow-up and participants with PAD at baseline were excluded for the association with PAD $(\mathrm{ABI}<0.9)$ population-based cohorts, the Atherosclerosis Risk in Communities (ARIC) cohort and the Multi-Ethnic Study of Atherosclerosis (MESA) cohort, cross-sectional and multivariable associations for dietary magnesium and IMT were absent $[29,30]$. In contrast, one smaller cohort study in healthy participants and one dietary intervention study in people with diabetes demonstrated age adjusted, inverse associations between (baseline) magnesium intake and IMT [31, 32]. However, these analyses were not energy- or fibre intake adjusted and also no association between magnesium intake and PWV was found [32]. To our knowledge, no studies have reported on dietary magnesium in relation to Aix, FMD or PAD. Other parameters of vascular structure and function such as coronary or aortic calcification, heart failure and blood pressure have been studied more frequently in relation to dietary magnesium, but these studies also revealed inconsistent results [5, 7, 10,51-55]. Fibre or 'diet' was an imported confounder in most of these studies, often attenuating or erasing associations when adjusted for. Adjustment for fibre intake also considerably influenced most of our analyses of vascular outcomes, although these associations were not significant in crude or in fully-adjusted models. We also considered confounding by physical activity, alcohol intake and, education, however, this did not materially change the results (data not shown).

The absence of associations between magnesium intake and all markers of vascular structure and function in this cohort contradicts the more established association between dietary magnesium intake and CVD and mortality observed in systematic reviews and meta-analyses [3-7]. Similarly, these results are not in line with the mainly confirmative studies of serum magnesium concentrations in relation to vascular outcomes [16-20, 56, 57]. These inconsistencies could be explained in several ways. First of all, due to complex magnesium homeostasis-balancing fractional magnesium absorption, shifts between intracellular and extracellular compartments, uptake and release form the bone and renal excretion-it is possible that dietary magnesium intake has no or too little effect on serum or total body magnesium and explain why no associations between magnesium intake and vascular parameters are found. Secondly, our sample size could be too small (lack of power) to demonstrate an association, since most confirmative studies were larger cohorts or meta-analyses. Furthermore, not all studies that 
found an inverse association between magnesium intake and (other) vascular markers adjusted for energy intake or dietary intake of other nutrients such as fibre and, therefore, possibly incorrectly attributed this association to magnesium intake, while in fact this may reflect a healthier diet or better nutritional status. Another explanation is the relatively high percentage of comorbidities of this vascular screening sub-cohort, including prior CVD (55\%), hypertension (70\%), DM2 (41\%) and IGT (23\%) and already unfavourable vascular outcomes at baseline. Based on the understanding that magnesium inhibits vascular calcification and inflammation rather than reversing established vascular impairment [58], we cannot exclude that the assumed beneficial effect of higher magnesium intake is too small to be detected in this already severely vascular affected high-risk population. In line, a recent sub-analysis of the ARIC cohort did not show an association between serum magnesium and PAD risk in high-risk individuals, while this association was present in the overall population-based cohort [59]. Lastly, the range of magnesium intake within a regular diet is relatively small. The absolute magnesium intake of $321 \mathrm{mg} /$ day (IQR of 273-375) within this cohort, is close to the European Food Safety Authority magnesium intake recommendation of $300 \mathrm{mg}$ and $350 \mathrm{mg}$ per day for adult women and men, respectively. Also the absolute dietary magnesium intake range of $109-701 \mathrm{mg} /$ day is close to the intake range of 96-425 mg/day described in a systematic review and metaanalysis of multiple prospective cohort studies on magnesium intake [10]. However, this dietary range may be too small to detect substantial and consistent associations on vascular parameters, hardly influencing serum magnesium levels. Magnesium intervention studies, mostly doubling daily magnesium intake (up to $610 \mathrm{mg}$ of elemental magnesium a day on top of dietary intake) are less vulnerable for confounding by dietary components accompanying a higher magnesium diet and are more likely to positively influence magnesium balance. Indeed, several-magnesium supplementation studies within comparable or even higher risk study populations did find an effect of magnesium supplementation on IMT, PWV and FMD [24-27, 60-62].

\section{Strengths and limitations}

The strengths of this study include its combination of a comprehensive set of markers of vascular structure and function in a single, cohort and its prospective design. In addition, the selection of a high-risk population with already unfavourable vascular outcomes at baseline is one of the strengths, since results of dietary exposure are generally most pronounced for those at high risk. To our knowledge, it is the first study that investigated dietary magnesium intake in relation to FMD, PAD and Aix. We were able to adjust for a variety of covariates, including energy and fibre intake and we could study the effect modification for glucose status, sex, age and a history of CVD.

A limitation of our study is the sample size that could have been insufficient to detect significant and clinically relevant differences for some of the vascular markers, potentially in the case of PWV [63] and for the risk of PAD. However, for IMT, FMD and Aix, the effect estimates and 95\% CI did not include clinical relevant differences [64], and, therefore, these null results are not due to lack of power but rather reflect very small differences. Another limitations is that assessment of magnesium intake with the FFQ was not validated to estimate magnesium intake. However, the FFQ was validated for other nutrients and correlated well with fibre intake and adequately ranks subjects according to intake of most food groups, energy and fibre intake [35, 36]. Therefore, we assume that the FFQ correctly ranks subjects according to their magnesium intake. With only estimated magnesium intake at baseline, possible dietary changes affecting magnesium intake during follow-up are not taken into account in the longitudinal association, though we can assume that dietary intake is relatively stable over the years [65]. Unfortunately, we only had follow-up measurements of three out of five vascular outcomes and although the majority of participants had measurements of all concerning vascular outcomes, missing data in outcome measurements could be due to measurement specific or participant-related complications, or simply because of separate visits for some vascular measurements. In addition, the longitudinal associations may be biased due to a selective and high rate of lost to follow-up (attrition bias). However, we observed similar results for the cross-sectional analyses of concerning outcome parameters. Every vascular measurement has its own limitations, but generally they are complex to perform and these measurements are subject to inter-individual variation and variation due to external factors, such as temperature, medicine or caffeine intake. Finally, inherent to our studies observational design, there may be residual confounding due to unmeasured factors. However, considering the overall absence of associations between magnesium intake and the vascular markers, residual confounding as well as adjustment for multiple testing would not change the results.

\section{Conclusions and future research}

Dietary intake of magnesium is not associated with vascular structure and function within this prospective cohort. It is unknown if a substantial higher magnesium intake in the general population may be beneficial for vascular outcome parameters. Therefore, we suggest future studies to focus on magnesium supplementation on top of dietary magnesium intake in relation to vascular outcomes, especially in a longterm and preventive setting. 
Supplementary Information The online version contains supplementary material available at https://doi.org/10.1007/s00394-021-02667-0.

Acknowledgments The authors thank all the participants, researchers and staff of the Hoorn cohort in Hoorn for their contributions.

Author contributions The Hoorn vascular screening sub-cohort data collection was performed in the years 2000-2009. Conceptualisation and methodology was performed by EV, supervised by JB, MV, AvB, $\mathrm{TH}$ and discussed in consortium meetings with $\mathrm{CE}$ and MdB. Material preparation, data collection and analyses were performed by EV and preliminary analyses and draft by students $\mathrm{HdJ}$ and $\mathrm{AB}$. The first draft of the manuscript was written by EV and all authors commented on previous versions of the manuscript. All authors read and approved the final manuscript.

Funding The Hoorn cohort was supported by the Dutch Diabetes Research Foundation [2005.00.010, 2003.01.004] and this research was supported by the NIGRAM2+ consortium, funded by Health Holland (LSHM17034) and the Dutch Kidney Foundation (16TKI02). J.W.J. Beulens is supported by a ZonMW NWO-Vidi grant (91718304).

\section{Declarations}

Conflict of interest The authors declare no conflict of interest.

Open Access This article is licensed under a Creative Commons Attribution 4.0 International License, which permits use, sharing, adaptation, distribution and reproduction in any medium or format, as long as you give appropriate credit to the original author(s) and the source, provide a link to the Creative Commons licence, and indicate if changes were made. The images or other third party material in this article are included in the article's Creative Commons licence, unless indicated otherwise in a credit line to the material. If material is not included in the article's Creative Commons licence and your intended use is not permitted by statutory regulation or exceeds the permitted use, you will need to obtain permission directly from the copyright holder. To view a copy of this licence, visit http://creativecommons.org/licenses/by/4.0/.

\section{References}

1. WHO (2018) Noncommunicable diseases, country profiles. World Health Organization, https://www.who.int/nmh/publications/ncdprofiles-2018/en/. Accessed 2 Apr 2020

2. WHO (2017) Cardiovascular Diseases, Key facts. World Health Organisation. https://www.who.int/health-topics/cardiovasculardiseases. Accessed on 2 april 2020

3. Zhao L, Hu M, Yang L, Xu H, Song W, Qian Y, Zhao M (2019) Quantitative association between serum/dietary magnesium and cardiovascular disease/coronary heart disease risk: a doseresponse meta-analysis of prospective cohort studies. J Cardiovasc Pharmacol 74(6):516-527. https://doi.org/10.1097/FJC.00000 00000000739

4. Fang X, Wang K, Han D, He X, Wei J, Zhao L, Imam MU, Ping Z, Li Y, Xu Y, Min J, Wang F (2016) Dietary magnesium intake and the risk of cardiovascular disease, type 2 diabetes, and allcause mortality: a dose-response meta-analysis of prospective cohort studies. BMC Med 14(1):210. https://doi.org/10.1186/ s12916-016-0742-Z

5. Zhao B, Zeng L, Zhao J, Wu Q, Dong Y, Zou F, Gan L, Wei Y, Zhang W (2020) Association of magnesium intake with type 2 diabetes and total stroke: an updated systematic review and meta-analysis. BMJ Open 10(3):e032240. https://doi.org/10.1136/ bmjopen-2019-032240

6. Larsson SC, Orsini N, Wolk A (2012) Dietary magnesium intake and risk of stroke: a meta-analysis of prospective studies. Am J Clin Nutr 95(2):362-366. https://doi.org/10.3945/ajen.111. 022376

7. Del Gobbo LC, Imamura F, Wu JH, de Oliveira Otto MC, Chiuve SE, Mozaffarian D (2013) Circulating and dietary magnesium and risk of cardiovascular disease: a systematic review and metaanalysis of prospective studies. Am J Clin Nutr 98(1):160-173. https://doi.org/10.3945/ajcn.112.053132

8. Rosique-Esteban N, Guasch-Ferre M, Hernandez-Alonso P, SalasSalvado J (2018) Dietary magnesium and cardiovascular disease: a review with emphasis in epidemiological studies. Nutrients. https://doi.org/10.3390/nu10020168

9. Jahnen-Dechent W, Ketteler M (2012) Magnesium basics Clin Kidney J 5(Suppl 1):i3-i14. https://doi.org/10.1093/ndtplus/ sfr163

10. Han H, Fang X, Wei X, Liu Y, Jin Z, Chen Q, Fan Z, Aaseth J, Hiyoshi A, He J, Cao Y (2017) Dose-response relationship between dietary magnesium intake, serum magnesium concentration and risk of hypertension: a systematic review and metaanalysis of prospective cohort studies. Nutr J 16(1):26. https://doi. org/10.1186/s 12937-017-0247-4

11. Leenders NHJ, Vervloet MG (2019) Magnesium: a magic bullet for cardiovascular disease in chronic kidney disease? Nutrients. https://doi.org/10.3390/nu11020455

12. Ter Braake AD, Smit AE, Bos C, van Herwaarden AE, Alkema W, van Essen HW, Bravenboer N, Vervloet MG, Hoenderop JGJ, de Baaij JHF (2020) Magnesium prevents vascular calcification in Klotho deficiency. Kidney Int 97(3):487-501. https://doi.org/ 10.1016/j.kint.2019.09.034

13. Moor MB, Ramakrishnan SK, Legrand F, Bachtler M, Koesters R, Hynes NE, Pasch A, Bonny O (2020) Elevated serum magnesium lowers calcification propensity in Memo1-deficient mice. PLoS ONE 15(7):e0236361. https://doi.org/10.1371/journal. pone. 0236361

14. Diaz-Tocados JM, Peralta-Ramirez A, Rodriguez-Ortiz ME, Raya AI, Lopez I, Pineda C, Herencia C, Montes de Oca A, Vergara N, Steppan S, Pendon-Ruiz de Mier MV, Buendia P, Carmona A, Carracedo J, Alcala-Diaz JF, Frazao J, MartinezMoreno JM, Canalejo A, Felsenfeld A, Rodriguez M, Aguilera-Tejero E, Almaden Y, Munoz-Castaneda JR (2017) Dietary magnesium supplementation prevents and reverses vascular and soft tissue calcifications in uremic rats. Kidney Int 92(5):10841099. https://doi.org/10.1016/j.kint.2017.04.011

15. Ter Braake AD, Tinnemans PT, Shanahan CM, Hoenderop JGJ, de Baaij JHF (2018) Magnesium prevents vascular calcification in vitro by inhibition of hydroxyapatite crystal formation. Sci Rep 8(1):2069. https://doi.org/10.1038/s41598-018-20241-3

16. Yorifuji M, Kuragano T, Kawada S, Fukao W, Toyoda K, Nakanishi T (2018) Factors associated with serum magnesium and vascular stiffness in maintenance hemodialysis patients. Hemodial Int 22(3):342-350. https://doi.org/10.1111/hdi.12625

17. Afsar B, Elsurer R (2014) The relationship between magnesium and ambulatory blood pressure, augmentation index, pulse wave velocity, total peripheral resistance, and cardiac output in essential hypertensive patients. J Am Soc Hypertens 8(1):28-35. https://doi.org/10.1016/j.jash.2013.10.006

18. Lee S, Ryu JH, Kim SJ, Ryu DR, Kang DH, Choi KB (2016) The relationship between magnesium and endothelial function in end-stage renal disease patients on hemodialysis. Yonsei Med J 57(6):1446-1453. https://doi.org/10.3349/ymj.2016.57.6.1446

19. Mancuso E, Perticone M, Spiga R, Averta C, Rubino M, Fiorentino TV, Miceli S, Mannino GC, Sciacqua A, Succurro E, Perticone F, Sesti G, Andreozzi F (2020) Association between serum 
$\mathrm{Mg}(2+)$ concentrations and cardiovascular organ damage in a cohort of adult subjects. Nutrients. https://doi.org/10.3390/ nu12051264

20. Cunha AR, Medeiros F, Umbelino B, Oigman W, Touyz RM, Neves MF (2013) Altered vascular structure and wave reflection in hypertensive women with low magnesium levels. J Am Soc Hypertens 7(5):344-352. https://doi.org/10.1016/j.jash.2013. 04.008

21. Salem S, Bruck H, Bahlmann FH, Peter M, Passlick-Deetjen J, Kretschmer A, Steppan S, Volsek M, Kribben A, Nierhaus M, Jankowski V, Zidek W, Jankowski J (2012) Relationship between magnesium and clinical biomarkers on inhibition of vascular calcification. Am J Nephrol 35(1):31-39. https://doi. org/10.1159/000334742

22. Chen W, Fitzpatrick J, Monroy-Trujillo JM, Sozio SM, Jaar BG, Estrella MM, Wu TT, Melamed ML, Parekh RS, Bushinsky DA (2019) Diabetes mellitus modifies the associations of serum magnesium concentration with arterial calcification and stiffness in incident hemodialysis Patients. Kidney Int Rep 4(6):806-813. https://doi.org/10.1016/j.ekir.2019.03.003

23. Del Giorno R, Lavorato Hadjeres S, Stefanelli K, Allegra G, Zapparoli C, Predrag L, Berwert L, Gabutti L (2020) Consequences of supraphysiological dialysate magnesium on arterial stiffness, hemodynamic profile, and endothelial function in hemodialysis: a randomized crossover study followed by a non-controlled follow-up phase. Adv Ther 37(12):4848-4865

24. Darooghegi Mofrad M, Djafarian K, Mozaffari H, Shab-Bidar S (2018) Effect of magnesium supplementation on endothelial function: a systematic review and meta-analysis of randomized controlled trials. Atherosclerosis 273:98-105. https://doi.org/10. 1016/j.atherosclerosis.2018.04.020

25. Marques B, Klein M, da Cunha MR, de Souza MS, de Paula NL, de Paula T, Correa FM, Oigman W, Neves MF (2020) Effects of oral magnesium supplementation on vascular function: a systematic review and meta-analysis of randomized controlled trials. High Blood Press Cardiovasc Prev 27(1):19-28. https://doi.org/ 10.1007/s40292-019-00355-z

26. Cunha AR, D’El-Rei J, Medeiros F, Umbelino B, Oigman W, Touyz RM, Neves MF (2017) Oral magnesium supplementation improves endothelial function and attenuates subclinical atherosclerosis in thiazide-treated hypertensive women. J Hypertens 35(1):89-97. https://doi.org/10.1097/HJH.0000000000001129

27. Mortazavi M, Moeinzadeh F, Saadatnia M, Shahidi S, Mcgee JC, Minagar A (2013) Effect of magnesium supplementation on carotid intima-media thickness and flow-mediated dilatation among hemodialysis patients: a double-blind, randomized. Placebo-Controlled Trial Eur Neurol 69(5):309-316. https://doi.org/ $10.1159 / 000346427$

28. Cosaro E, Bonafini S, Montagnana M, Danese E, Trettene MS, Minuz P, Delva P, Fava C (2014) Effects of magnesium supplements on blood pressure, endothelial function and metabolic parameters in healthy young men with a family history of metabolic syndrome. Nutr Metab Cardiovasc Dis 24(11):1213-1220. https://doi.org/10.1016/j.numecd.2014.05.010

29. Ma J, Folsom AR, Melnick SL, Eckfeldt JH, Sharrett AR, Nabulsi AA, Hutchinson RG, Metcalf PA (1995) Associations of serum and dietary magnesium with cardiovascular disease, hypertension, diabetes, insulin, and carotid arterial wall thickness: the ARIC study Atherosclerosis Risk in Communities Study. J Clin Epidemiol 48(7):927-940. https://doi.org/10.1016/0895-4356(94) 00200-a

30. de Oliveira Otto MC, Alonso A, Lee DH, Delclos GL, Jenny NS, Jiang R, Lima JA, Symanski E, Jacobs DR Jr, Nettleton JA (2011) Dietary micronutrient intakes are associated with markers of inflammation but not with markers of subclinical atherosclerosis. J Nutr 141(8):1508-1515. https://doi.org/10.3945/jn.111.138115
31. Masley SC, Roetzheim R, Masley LV, McNamara T, Schocken DD (2015) Emerging risk factors as markers for carotid intima media thickness scores. J Am Coll Nutr 34(2):100-107. https://doi.org/ 10.1080/07315724.2014.916238

32. Petersen KS, Keogh JB, Lister NB, Clifton PM (2018) Dietary quality and carotid intima media thickness in type 1 and type 2 diabetes: Follow-up of a randomised controlled trial. Nutr Metab Cardiovasc Dis 28(8):830-838. https://doi.org/10.1016/j.numecd. 2018.05.001

33. Rutters F, Nijpels G, Elders P, Stehouwer CDA, van der Heijden AA, Groeneveld L, tHart LM, Dekker JM, Beulens JWJ (2018) Cohort Profile: The Hoorn Studies. Int J Epidemiol 47(2):396396j. https://doi.org/10.1093/ije/dyx227

34. Spijkerman AM, Adriaanse MC, Dekker JM, Nijpels G, Stehouwer CD, Bouter LM, Heine RJ (2002) Diabetic patients detected by population-based stepwise screening already have a diabetic cardiovascular risk profile. Diabetes Care 25(10):1784-1789. https://doi.org/10.2337/diacare.25.10.1784

35. Ocke MC, BuenoDeMesquita HB, Goddijn HE, Jansen A, Pols MA, VanStaveren WA, Kromhout D (1997) The Dutch EPIC food frequency questionnaire.1. Description of the questionnaire, and relative validity and reproducibility for food groups. Int J Epidemiol 26:S37-S48

36. Ocke MC, Bueno-de-Mesquita HB, Pols MA, Smit HA, van Staveren WA, Kromhout D (1997) The Dutch EPIC food frequency questionnaire relative validity and reproducibility for nutrients. Int J Epidemiol. https://doi.org/10.1093/ije/26.suppl_1. s49

37. Stichting Nederlands Voedingsstoffenbestand (1993) NEVO tabel. Voorlichtingsbureau voor de Voeding, Den Haag

38. Henry RM, Kostense PJ, Spijkerman AM, Dekker JM, Nijpels G, Heine RJ, Kamp O, Westerhof N, Bouter LM, Stehouwer CD, Hoorn S (2003) Arterial stiffness increases with deteriorating glucose tolerance status: the Hoorn Study. Circulation 107(16):20892095. https://doi.org/10.1161/01.CIR.0000065222.34933.FC

39. Henry RMA, Ferreira I, Kostense PJ, Dekker JM, Nijpels G, Heine RJ, Kamp O, Bouter LM, Stehouwer CDA (2004) Type 2 diabetes is associated with impaired endothelium-dependent, flowmediated dilation, but impaired glucose metabolism is not-The Hoorn study. Atherosclerosis 174(1):49-56. https://doi.org/10. 1016/j.atherosclerosis.2004.01.002

40. Schram MT, Henry RM, van Dijk RA, Kostense PJ, Dekker JM, Nijpels G, Heine RJ, Bouter LM, Westerhof N, Stehouwer CD (2004) Increased central artery stiffness in impaired glucose metabolism and type 2 diabetes: the Hoorn Study. Hypertension 43(2):176-181. https://doi.org/10.1161/01.HYP.0000111829. 46090.92

41. van Sloten TT, Schram MT, van den Hurk K, Dekker JM, Nijpels G, Henry RM, Stehouwer CD (2014) Local stiffness of the carotid and femoral artery is associated with incident cardiovascular events and all-cause mortality: the Hoorn study. J Am Coll Cardiol 63(17):1739-1747. https://doi.org/10.1016/j.jacc.2013.12.041

42. Van Bortel LM, Laurent S, Boutouyrie P, Chowienczyk P, Cruickshank JK, De Backer T, Filipovsky J, Huybrechts S, Mattace-Raso FU, Protogerou AD, Schillaci G, Segers P, Vermeersch S, Weber T, Artery S, European Society of Hypertension Working Group on Vascular S, Function, European Network for Noninvasive Investigation of Large A (2012) Expert consensus document on the measurement of aortic stiffness in daily practice using carotidfemoral pulse wave velocity. J Hypertens 30(3):445-448. https:// doi.org/10.1097/HJH.0b013e32834fa8b0

43. Weber T, Ammer M, Rammer M, Adji A, O'Rourke MF, Wassertheurer S, Rosenkranz S, Eber B (2009) Noninvasive determination of carotid-femoral pulse wave velocity depends critically on assessment of travel distance: a comparison with invasive 
measurement. J Hypertens 27(8):1624-1630. https://doi.org/10. 1097/HJH.0b013e32832cb04e

44. Hanssen NMJ, Huijberts MS, Schalkwijk CG, Nijpels G, Dekker JM, Stehouwer CDA (2012) Associations between the ankle-brachial index and cardiovascular and all-cause mortality are similar in individuals without and with type 2 diabetes. Nineteen-year Follow-up Population-Based Cohort Study 35(8):1731-1735. https://doi.org/10.2337/dc12-0178

45. Beks PJ, Mackaay AJ, de Neeling JN, de Vries H, Bouter LM, Heine RJ (1995) Peripheral arterial disease in relation to glycaemic level in an elderly Caucasian population: the Hoorn study. Diabetologia 38(1):86-96

46. Rac-Albu M, Iliuta L, Guberna SM, Sinescu C (2014) The role of ankle-brachial index for predicting peripheral arterial disease. Maedica 9(3):295-302

47. WHO (1999) Definition, diagnosis and classification of diabetes mellitus and its complications: report of a WHO consultation. Part 1, Diagnosis and classification of diabetes mellitus. World Health Organization.

48. Rose GA (1962) The diagnosis of ischaemic heart pain and intermittent claudication in field surveys. Bull World Health Organ 27:645-658

49. Levey AS, Stevens LA, Schmid CH, Zhang YL, Castro AF 3rd, Feldman HI, Kusek JW, Eggers P, Van Lente F, Greene T, Coresh J (2009) A new equation to estimate glomerular filtration rate. Ann Intern Med 150(9):604-612. https://doi.org/10.7326/00034819-150-9-200905050-00006

50. Willett W (2013) Nutritional epidemiology, 3rd edn. Oxford University Press, New York

51. Hruby A, O'Donnell CJ, Jacques PF, Meigs JB, Hoffmann U, McKeown NM (2014) Magnesium intake is inversely associated with coronary artery calcification. Jacc-Cardiovasc Imag 7(1):59_ 69. https://doi.org/10.1016/j.jcmg.2013.10.006

52. Singh RB, Niaz MA, Moshiri M, Zheng G, Zhu S (1997) Magnesium status and risk of coronary artery disease in rural and urban populations with variable magnesium consumption. Magnes Res 10(3):205-213

53. Gant CM, Soedamah-Muthu SS, Binnenmars SH, Bakker SJL, Navis G, Laverman GD (2018) Higher dietary magnesium intake and higher magnesium status are associated with lower prevalence of coronary heart disease in patients with type 2 diabetes. Nutrients. https://doi.org/10.3390/nu10030307

54. Wu WC, Huang M, Taveira TH, Roberts MB, Martin LW, Wellenius GA, Johnson KC, Manson JE, Liu S, Eaton CB (2020) Relationship between dietary magnesium intake and incident heart failure among older women: the WHI. J Am Heart Assoc 9(7):e013570. https://doi.org/10.1161/JAHA.119.013570

55. Jee SH, Miller ER 3rd, Guallar E, Singh VK, Appel LJ, Klag MJ (2002) The effect of magnesium supplementation on blood pressure: a meta-analysis of randomized clinical trials. Am J Hypertens 15(8):691-696. https://doi.org/10.1016/s0895-7061(02) 02964-3
56. Sun X, Zhuang X, Huo M, Feng P, Zhang S, Zhong X, Zhou H, Guo Y, Hu X, Du Z, Zhang M, Liao X (2019) Serum magnesium and the prevalence of peripheral artery disease: the Atherosclerosis Risk in Communities (ARIC) study. Atherosclerosis 282:196-201. https://doi.org/10.1016/j.atherosclerosis.2018.12. 004

57. Cao Y, Wang C, Guan K, Xu Y, Su YX, Chen YM (2016) Association of magnesium in serum and urine with carotid intima-media thickness and serum lipids in middle-aged and elderly Chinese: a community-based cross-sectional study. Eur J Nutr 55(1):219 226. https://doi.org/10.1007/s00394-015-0839-8

58. Ter Braake AD, Eelderink C, Zeper LW, Pasch A, Bakker SJL, de Borst MH, Hoenderop JGJ, de Baaij JHF (2019) Calciprotein particle inhibition explains magnesium-mediated protection against vascular calcification. Nephrol Dial Transplant. https://doi.org/10. 1093/ndt/gfz190

59. Menez S, Ding N, Grams ME, Lutsey PL, Heiss G, Folsom AR, Selvin E, Coresh J, Jaar BG, Matsushita K (2020) Serum magnesium, bone-mineral metabolism markers and their interactions with kidney function on subsequent risk of peripheral artery disease: the Atherosclerosis Risk in Communities Study. Nephrol Dial Transplant. https://doi.org/10.1093/ndt/gfaa029

60. Joris PJ, Plat J, Bakker SJ, Mensink RP (2016) Long-term magnesium supplementation improves arterial stiffness in overweight and obese adults: results of a randomized, double-blind, placebocontrolled intervention trial. Am J Clin Nutr 103(5):1260-1266. https://doi.org/10.3945/ajcn.116.131466

61. Talari HR, Zakizade M, Soleimani A, Bahmani F, Ghaderi A, Mirhosseini N, Eslahi M, Babadi M, Mansournia MA, Asemi Z (2019) Effects of magnesium supplementation on carotid intimamedia thickness and metabolic profiles in diabetic haemodialysis patients: a randomised, double-blind, placebo-controlled trial. Br J Nutr 121(7):809-817. https://doi.org/10.1017/S00071145190001 63

62. Barbagallo M, Dominguez LJ, Galioto A, Pineo A, Belvedere M (2010) Oral magnesium supplementation improves vascular function in elderly diabetic patients. Magnes Res 23(3):131-137. https://doi.org/10.1684/mrh.2010.0214

63. Vlachopoulos C, Aznaouridis K, Stefanadis C (2010) Prediction of cardiovascular events and all-cause mortality with arterial stiffness a systematic review and meta-analysis. J Am Coll Cardiol 55(13):1318-1327. https://doi.org/10.1016/j.jacc.2009.10.061

64. Lorenz MW, Markus HS, Bots ML, Rosvall M, Sitzer M (2007) Prediction of clinical cardiovascular events with carotid intimamedia thickness: a systematic review and meta-analysis. Circulation 115(4):459-467. https://doi.org/10.1161/CIRCULATIO NAHA.106.628875

65. Nagel G, Zoller D, Ruf T, Rohrmann S, Linseisen J (2007) Longterm reproducibility of a food-frequency questionnaire and dietary changes in the European Prospective Investigation into Cancer and Nutrition (EPIC)-Heidelberg cohort. Br J Nutr 98(1):194-200. https://doi.org/10.1017/S0007114507691636 